\title{
FAST PACE OF LIFE AND ITS IMPACT ON HEALTH: RESULTS OF A STUDY FROM THE LARGEST CITY OF PAKISTAN
}

\author{
Waris Qidwai ${ }^{1}$, Imdad Ali Khushk², Uzma Shamim ${ }^{3}$, Saima Altaf ${ }^{4}$, Hina Hadi $^{5}$, Kashmira Nanji $^{6}$
}

${ }^{1,5,6}$ Family Medicine Department, Aga Khan University Karachi Pakistan, ${ }^{2}$ Pakistan Medical \& Dental Council Islamabad, 3,4Medical College, Dow University of Health Sciences, Karachi Pakistan

Corresponding Author: Kashmira Nanji, Sr. Instructor (Research), Family Medicine Department, Aga Khan University Karachi Pakistan, Email: kashmira.nanji@aku.edu, Tel: (92-21) 486-4843, 486-4868, Fax: (92-21) 4934294, 493-2095

\begin{abstract}
Background: Increasing modernization and mechanization have turned the life into fast pace and it has devastating effects on the health of the people.

Objective:To identify the perceptions of patients regarding fast pace of life and its impact on health.

Methods: A cross-sectional study was conducted at out-patients department of two tertiary care hospitals in Karachi, Pakistan; from January to March 2013. A total of 401 participants aged $>18$ years were recruited through consecutive sampling. Data analysis was done using SPSS 19.0 and multivariable logistic regression was applied to identify impact of fast life.

Results: Out of total 401 participants, $55 \%$ of the patients were between $21-35$ years of age and majority was females $(75 \%)$. Majority of the participants was suffering from fast pace life $(82 \%)$ and main reasons for fast pace life were competition and the increasing needs of the family. Those who were suffering from fast pace life were at risk of affecting their physical health (AOR: 2.6; 95\% C.I:1.3-5.2), social life (AOR: 2.195\% C.I:1.0-4.5), psychological wellbeing (AOR: 2.4; 95\% C.I:1.2-4.5) and are more susceptible to stress and depression (AOR: 4.6; 95\% C.I:2.3-9.3).

Conclusion: This study found that majority of urban population is suffering from fast pace of life with severe consequences on its physical, social and mental health. The society seems to be speeding up and becoming less empathic and increasingly stressful. This will have delirious effects on physical and mental health of people in the decades to come. Therefore, it is important for people to take time out for themselves and their families to keep themselves fit for survival in this fast moving world.
\end{abstract}

Key words: Fast pace, physical health, mental health, spiritual health,

\section{Introduction:}

One of the blessings of 21st century is the global increase in mechanization and industrialization, which has extraordinarily minimized the time required to complete a task[1]. Despite of this huge advantage that urbanization bestows on the human race, there never seems to be enough time to even appreciate the minor pleasures of life. The prominent German environmental thinker Wolfgang Sachs said in his report:

"A lot of energy is put into raising kids, making friends, creating art, running counter to the demand of speed. There is growing recognition that faster speeds are not just a natural fact of the universe. It's an issue for public attention" [2].

In literal terms, the pace of life has been defined using rate, speed, and "relative rapidity or density of experiences, meanings, perceptions and activities"[3]. Thus fast paced life denotes a life that is transforming very swiftly. A study carried out in early 1990s demonstrated that people in fast-moving cities are less likely to help others and have higher rates of coronary heart disease [4]. Similar study conducted by British Council, who secretly timed thousands of pedestrians' speed of walking in city centers across the globe including London, Madrid, Singapore, and New York revealed that the pace of life is now $10 \%$ faster than in the early 1990s [5]. The biggest changes were found in the Far East, with the pace of life in Guangzhou [China] increasing by over $20 \%$, and Singapore showing a $30 \%$ increase, resulting in becoming the fastest moving city in the study [6].

The pace of life in major cities is now much quicker than before. Researchers believe that this increase in speed will affect more people than ever, because majority of the world's population is now living in urban centers [7]. Several other studies have reported differences and similarities in pace of life between urban and rural communities [8]. Studies have shown the positive association between pace of life and heart diseases, attributed mainly to stress and way of living [9]. It is also well-evident that fast paced lifestyle and mechanization has evidently decreased physical activity among people 
and increased the incidence of obesity, stress, smoking, diabetes and other health issues [10-11]. Spending time with the family is an effective strategy to de-stress and meal times are the best time to mingle with the family [12]. However, a recent study from India has revealed that 10 per cent of the 2,000 parents polled, never have a family meal and less than a third sit down to one every night. Fifteen per cent blamed a lengthy commute and one in five said domestic chores got in the way of a good family get-together [12].

The studies have concluded that fast paced life is a hazard, either from the health or the economical aspect [11]. There is no or very limited data available from Pakistan on this important issue. Therefore, the present study was conducted to identify the perceptions of patients regarding fast pace life and its impact on health of people living in a developing country [Pakistan].

\section{Methodology:}

This cross-sectional study was carried out from January to March 2013 at out-patients department (OPD) of two tertiary care hospitals i.e. Civil Hospital and Aga Khan University Hospital (AKUH) in Karachi. Karachi is the largest and most populous city of Pakistan. These OPD clinics were chosen to obtain a diverse sample belonging to various socio-economic strata. The patients who visited the OPD clinics of study hospitals, having more than 18 years of age and gave consent to participate were included in the study. However, patients suffering from serious co-morbid conditions like cancer, advance heart failure or terminal renal failure and those who needed special care; intensive care unit or coronary care unit admissions were excluded. A total of 500 adult patients were consecutively approached to take part in this study, out of which 401 (80.2\%) agreed to participate and were interviewed.

Participants were interviewed through a pre-tested and structured questionnaire comprising of two sections; socio-demographic profile and effects of fast pace life on physical, psychological and spiritual health. The questionnaire was formulated after thorough literature search and it was shared with experts in the field of family medicine to obtain their suggestions for improvement. The English version of the questionnaire was prepared first and then it was translated into Urdu language. It was back translated in English to check for consistency and to remove any discrepancies. The pretesting of the Urdu version was done on 20 participants, approximately $5 \%$ of the total sample size.

In this study, fast pace life was defined according to the questions used by Prof Richard Wiseman (University of Hertfordshire) who in his study measured the speed of life in 32 countries. The following questions were asked from the respondents and 5 or more 'yes' responses on the 07 item questions, suggested the participant is having a fast life. The questions included:

1) Do you seem to glance at your watch more than others?

2) When someone takes too long to get to the point, do you feel like hurrying them along?

3)Are you often the first person to finish at meal times?

4) When walking along a street, do you often feel frustrated because you are stuck behind others?

5) Would you become irritable if you sit for an hour without doing anything?

6) Do you walk out of restaurants or shops if you encounter even a short queue?

7) If you are caught in slow-moving traffic, do you seem to get more annoyed than other drivers?

The respondents were also asked about what they believe is the 'cause' of this rapid change and what is their prediction regarding pace of life in the coming years.

Medical graduates were trained for data collection. The data collection was done when the patients came out of the consultation room (exit interview) to avoid chances of recall bias.

Written informed consent was obtained from all participants after explaining them about the study protocol. All study personnel were trained in procedures for maintaining confidentiality of the information obtained. No personal identifiers were used in any report or publication arising from this study. The study was conducted in accordance with the 'Ethical principles for medical research involving human subjects' of Helsinki Declaration. The study was reviewed and approved by the Family Medicine research committee at AKUH.

Statistical Analysis:

This study did not have any a priori hypothesis so power analysis was not performed. The data was entered in Epi Data version 3.1 and analyzed in Statistical Package for Social Sciences 19.0 (SPSS, Inc., Chicago, IL, USA). Descriptive statistics was performed and proportions were reported for all the categorical variables. Pearson chi-square test and univariate logistic regression was used to identify the factors associated with dependent variable by calculating the crude odds ratios at $95 \%$ confidence interval $(\mathrm{Cl})$. The variables with $\mathrm{p}$-value of $<$ 0.25 at univariate level were then stepwise entered to multivariable logistic regression. Results were reported in form of adjusted odds ratios with $95 \% \mathrm{Cl}$. Statistical significance was considered at $p$-value of $<0.05$ throughout the analysis except at the univariate level.

\section{Results:}

A total of 401 patients' information was included in final analysis. Around $55 \%$ of the patients were between 21 35 years while only $8.7 \%$ were more than 50 years of age. About $75 \%$ of the participants were females and $37 \%$ were never married. Moreover, $41 \%$ of the patients had 11 to 16 years of schooling while $19.5 \%$ could not read or write. Approximately $32 \%$ of the patients were self-employed, $18 \%$ students and $42 \%$ were housewives (table 1 ). 
Table 1: Socio-demographic characteristics of the study participants $(n=401)$

\begin{tabular}{|l|l|l|}
\hline Variable & $\mathrm{N}$ & $\%$ \\
\hline Age & & \\
\hline Less than 20 years & 60 & 15 \\
\hline $21-35$ years & 220 & 54.9 \\
\hline $36-50$ years & 86 & 21.4 \\
\hline$>50$ years & 35 & 8.7 \\
\hline Gender & & \\
\hline Male & 101 & 25.2 \\
\hline Female & 300 & 74.8 \\
\hline Marital status & & \\
\hline Never married & 150 & 37.4 \\
\hline Married & 251 & 62.6 \\
\hline Educational status & & \\
\hline Can't read or write & 78 & 19.5 \\
\hline Upto 5 years of education & 22 & 5.5 \\
\hline 6-10 years of education & 80 & 20 \\
\hline $11-16$ years of education & 165 & 41 \\
\hline$>16$ years & 56 & 14 \\
\hline Occupation & 169 & 42.1 \\
\hline Self-employed & 32 & 8 \\
\hline Un-employed & 72 & 18 \\
\hline Student & & \\
\hline Housewife & & \\
\hline
\end{tabular}

Table 2 depicts the socio-demographic factors related to fast pace life. Majority of the participants were suffering from fast pace life $(82 \%)$. The highest percentage of participants who reported to be a victim of fast pace life were between 21 to 35 years age (55.6\%), had at least 11-16 years of education and being female. Housewives also responded that they are affected by the fast pace life. Table 3 shows impact of fast pace life on the health of the patients. Majority ( $82 \%)$ of the patients believed that they were a victim of fast pace life. The patients responded that due to increasing needs $(56.5 \%)$ and competition (17.3\%) the lives have become fast. There was a preponderance of participants who believe that fast pace life is affecting their physical health $(86 \%, p$ value 0.001$)$, social health $(76.3 \%, p$ value 0.001$)$ and spiritual life $(55 \%, p$ value 0.001$)$. Both the groups responded that fast pace life is affecting their family life $(65.7 \%$ vs $54.2 \%)$. Approximately $92 \%$ of the participants responded that fast pace life is affecting them psychologically and it will continue in years to come $(93 \%)$.

Table 2: Socio-demographic variables related to fast pace life

\begin{tabular}{|c|c|c|c|}
\hline \multirow[t]{2}{*}{ Variable } & \multicolumn{2}{|c|}{ Victim of fast pace life } & \multirow{2}{*}{$\begin{array}{l}P \text { - } \\
\text { value }\end{array}$} \\
\hline & $\begin{array}{c}\text { Yes } \\
(n=329)\end{array}$ & $\begin{array}{c}\text { No } \\
(n=72)\end{array}$ & \\
\hline \multicolumn{4}{|l|}{ Age (in years) } \\
\hline less than 20 & $48(14.6)$ & $12(16.7)$ & \multirow{4}{*}{0.92} \\
\hline $21-35$ & $183(55.6)$ & $37(51.4)$ & \\
\hline $36-50$ & $70(21.3)$ & $16(22.2)$ & \\
\hline$>50$ & $28(8.5)$ & $7(9.7)$ & \\
\hline \multicolumn{4}{|l|}{ Gender } \\
\hline Male & $84(25.5)$ & $17(23.6)$ & \multirow[b]{2}{*}{0.73} \\
\hline Female & $245(74.5)$ & $55(76.4)$ & \\
\hline \multicolumn{4}{|l|}{ Marital status } \\
\hline Never married & $127(38.6)$ & $23(31.9)$ & \multirow[b]{2}{*}{0.29} \\
\hline Married & $202(61.4)$ & $49(68.1)$ & \\
\hline \multicolumn{4}{|l|}{ Educational status } \\
\hline Can't read or write & $69(21.0)$ & $9(12.5)$ & \multirow{5}{*}{0.17} \\
\hline Primary (1-5) & $17(5.2)$ & $5(6.9)$ & \\
\hline $\begin{array}{l}6-10 \text { years of } \\
\text { education }\end{array}$ & $63(19.1)$ & $17(23.6)$ & \\
\hline $\begin{array}{l}11-16 \text { years of } \\
\text { education }\end{array}$ & $130(39.5)$ & $35(48.6)$ & \\
\hline$>16$ years of education & $50(15.2)$ & $6(8.3)$ & \\
\hline \multicolumn{4}{|l|}{ Occupation } \\
\hline Self-employed & $105(31.9)$ & $23(31.9)$ & \multirow{3}{*}{0.698} \\
\hline Un-employed & $24(7.3)$ & $8(11.1)$ & \\
\hline Student & $61(18.5)$ & $11(15.3)$ & \\
\hline Housewife & $139(42.2)$ & $30(41.7)$ & \\
\hline
\end{tabular}


Table 3: Reasons and Impact of leading a fast pace life

\begin{tabular}{|c|c|c|c|}
\hline \multirow{2}{*}{$\begin{array}{l}\text { Variable } \\
\text { Little time for self and family }\end{array}$} & $\begin{array}{l}\text { Victim of } \mathrm{f} \\
\text { Yes } \\
(n=329)\end{array}$ & $\begin{array}{l}\text { t pace life } \\
\text { No } \\
n=72)\end{array}$ & \multirow[t]{2}{*}{ P-value } \\
\hline & & & \\
\hline Yes & $295(89.7)$ & $50(69.4)$ & \multirow{2}{*}{$<0.001$} \\
\hline No & $34(10.3)$ & $22(30.6)$ & \\
\hline \multicolumn{4}{|l|}{ Reasons for fast pace life? } \\
\hline Increasing competition & $57(17.3)$ & $18(25.0)$ & 0.141 \\
\hline Needs have increased & $186(56.5)$ & $32(44.4)$ & \\
\hline Become more materialistic & $43(13.1)$ & $7(9.7)$ & \\
\hline Priorities have changed & $31(9.4)$ & $12(16.7)$ & \\
\hline Expectations have increased & $12(3.6)$ & $3(4.2)$ & \\
\hline \multicolumn{4}{|l|}{$\begin{array}{l}\text { Fast pace affecting physical } \\
\text { life? }\end{array}$} \\
\hline Yes & $283(86.0)$ & $44(61.1)$ & $<0.001$ \\
\hline No & $46(14.0)$ & $28(38.9)$ & \\
\hline \multicolumn{4}{|l|}{$\begin{array}{l}\text { Fast pace affecting social } \\
\text { life? }\end{array}$} \\
\hline Yes & $251(76.3)$ & $37(51.4)$ & $<0.001$ \\
\hline No & $78(23.7)$ & $35(48.6)$ & \\
\hline \multicolumn{4}{|l|}{$\begin{array}{l}\text { Fast pace affecting family } \\
\text { life? }\end{array}$} \\
\hline Yes & $216(65.7)$ & $39(54.2)$ & 0.067 \\
\hline No & $113(34.3)$ & $33(45.8)$ & \\
\hline \multicolumn{4}{|l|}{$\begin{array}{l}\text { Fast pace affecting spiritual } \\
\text { life? }\end{array}$} \\
\hline Yes & $182(55.3)$ & $24(33.3)$ & $<0.001$ \\
\hline No & $147(44.7)$ & $48(66.7)$ & \\
\hline \multicolumn{4}{|c|}{ Fast pace affecting psychological well-being? } \\
\hline Yes & $268(81.5)$ & $36(50.0)$ & $<0.001$ \\
\hline No & $61(18.5)$ & $36(50.0)$ & \\
\hline \multicolumn{4}{|l|}{ Fast pace affecting work life? } \\
\hline Yes & $147(44.7)$ & $25(34.7)$ & 0.122 \\
\hline No & $182(55.3)$ & $47(65.3)$ & \\
\hline \multicolumn{4}{|l|}{$\begin{array}{l}\text { Fast pace causing stress and } \\
\text { depression? }\end{array}$} \\
\hline Yes & $302(91.8)$ & $44(61.1)$ & $<0.001$ \\
\hline No & $27(8.2)$ & $28(38.9)$ & \\
\hline
\end{tabular}

\begin{tabular}{|l|l|l|l|}
\hline Slow down your life? & & & \\
\hline Yes & $286(81.5)$ & $40(55.6)$ & $<0.001$ \\
\hline No & $61(18.5)$ & $32(44.4)$ & \\
\hline $\begin{array}{l}\text { Feel helpless in slowing } \\
\text { down? }\end{array}$ & & & \\
\hline Yes & $233(70.8)$ & $33(45.8)$ & $<0.001$ \\
\hline No & $96(29.2)$ & $39(54.2)$ & \\
\hline $\begin{array}{l}\text { Life becoming faster in years } \\
\text { to come? }\end{array}$ & & & \\
\hline Yes & $309(93.3)$ & $66(91.7)$ & 0.482 \\
\hline No & $20(6.1)$ & $6(8.3)$ & \\
\hline
\end{tabular}

The factors associated with fast life and its effect on health (physical, mental, psychological) is given in table 4. Those who were suffering from fast pace life are at risk of affecting their physical health (AOR: 2.6; 95\% C.I:1.35.2), social life (AOR: 2.1 95\% C.I:1.0-4.5), psychological well-being (AOR: 2.4; 95\% C.I:1.2-4.5) and are more prone to stress and depression (AOR: 4.6; $95 \%$ C.I:2.3-9.3) when adjusted for other variables in the model.

Table 4: Impact of Fast Pace life on Health $(n=401)$

\begin{tabular}{|c|c|c|c|c|}
\hline Variable & $\begin{array}{c}\text { Odds Ratio } \\
(95 \% \mathrm{Cl})\end{array}$ & $\begin{array}{c}\text { P- } \\
\text { Value }\end{array}$ & $\begin{array}{c}\text { Adjusted } \\
\text { Odds Ratio } \\
(95 \% \mathrm{Cl})\end{array}$ & P-Value \\
\hline \multicolumn{5}{|c|}{ Fast pace affecting physical life? } \\
\hline No & 1 & & 1 & \\
\hline Yes & $3.9(2.2-6.9)$ & $<0.001$ & $2.6(1.3-5.2)$ & $<0.001$ \\
\hline \multicolumn{5}{|c|}{ Fast pace affecting social life? } \\
\hline No & 1 & & 1 & \\
\hline Yes & $3.0(1.7-5.1)$ & $<0.001$ & $2.1(1.0-4.5)$ & 0.41 \\
\hline \multicolumn{5}{|c|}{ Fast pace affecting family life? } \\
\hline No & 1 & & 1 & \\
\hline Yes & $1.6(0.9-2.7)$ & 0.68 & $0.4(0.2-0.9)$ & 0.39 \\
\hline \multicolumn{5}{|c|}{ Fast pace affecting spiritual life? } \\
\hline No & 1 & & --- & \\
\hline Yes & $2.4(1.4-4.2)$ & $<0.001$ & & \\
\hline \multicolumn{5}{|c|}{ Fast pace affecting psychological well-being? } \\
\hline No & 1 & & 1 & \\
\hline Yes & $4.3(2.5-7.5)$ & $<0.001$ & $2.4(1.2-4.5)$ & 0.007 \\
\hline \multicolumn{5}{|c|}{ Fast pace affecting work life? } \\
\hline No & 1 & & & \\
\hline Yes & $1.5(0.8-2.5)$ & 0.124 & ----- & \\
\hline \multicolumn{5}{|c|}{ Fast pace people are prone to stress, anxiety, depression } \\
\hline No & 1 & & 1 & \\
\hline Yes & $7.1(3.8-13.1)$ & $<0.001$ & $4.6(2.3-9.3)$ & $<0.001$ \\
\hline
\end{tabular}




\section{Discussion:}

This is the first study to estimate the proportion of people leading fast pace life in Karachi, Pakistan and how it affects them. The results show that $82 \%$ of the participants were leading a fast pace life, which has affected their physical, psychological and spiritual health. The participants responded that the main reason for leading a fast pace life is because of the competition and the increasing needs of the family. This is true for most of the developing countries where the economies are not growing and the expenses are increasing day by day even for the basic necessities [7]. The weak and exhaustive health structure and the governments of these countries cannot provide affordable health care and education for the young [13]. Therefore the responsibility of providing quality education and health lies with the parents. This puts them under immense stress and to meet both ends they have to live a fast life, leaving the pleasures of little happiness in life.

In early 1900 s the scientists believed that stress was not bad, and in fact, it protects humans through fight-or-flight response which helped keep human beings alive when their environment demanded quick physical reactions in response to threats. However, this theory is opposite in modern times. In this era our body's stress response is regularly triggered by one or the other stressor [14]. Chronic exposure to stress hormones can damage the body. The otherwise functional role of cortisol production has the unintended effect of breaking down important physiological processes [9]. This process, described as allostasis or allostatic load may have deleterious associations with cardiovascular, metabolic, immune systems, brain activity, or central nervous system functioning [9]. This is consistent with the results of the study wherein $86 \%$ of the participants who were leading a fast pace life believed that this has affected their physical health. In Asian population, central obesity is found to be more common [15]. According to National Health Survey of Pakistan, $25 \%$ of our population is obese. One of the common reasons of not doing physical exercise is lack of time [16]. Exercises can in fact help in releasing endorphins which can assist in reducing stress $[17,18]$. Taking frequent effective exercise is one of the best physical stress-reduction techniques available. The incidence of T2DM worldwide is rising exponentially due to increase in sedentary life style leading to central abdominal obesity [16]. The American Psychological Association conducted a survey on stress in 2010. One of the findings from the survey was that stress experienced by women was increasing [19]. Despite the incredible amount of research over the past two decades on religion, spirituality and health, the relationship between religion and health remains poorly understood. Cross-sectional studies have shown an association between religion, better mental health and greater well-being $[14,20]$. Prospective studies have also found that religious beliefs and practices predict better mental health across time, with studies ranging in follow-up from a few months to decades [21,22]. Thus, research from prospective studies and randomized clinical trials supports the hypothesis that religious beliefs and practices may indeed influence mental health [23]. This seems quite plausible, since religious beliefs and teachings are generally supportive of social responsibility, healthy in terms of forbidding drugs and alcohol and enhance social support $[14,24]$. Religious communities also provide environment that promotes optimism regarding the future and giving people's lives purpose and meaning independent of their health and material circumstances [25-27]. However, in today's world people especially the younger generation does not have time to fulfill their religious obligations and practices, which creates a sense of emptiness and with no or limited social support the person has high chances of getting frustrated, arrogant and stressed [13].

One of the major drawbacks of this increasingly modern and fast life is limited time for self and family which can be the root cause of many problems and can lead to devastating situations [13]. In this study, about $66 \%$ of the participants felt that fast life had affected their family life. The increase in the competition and the need to be ahead from the fellow colleagues and friends results in less time with spouse, lower marital quality and consequently divorce [28]. In the last two decades there is a rise in divorce rate in Pakistan. One of the main reasons of these divorces was spousal complaints of lack of time spent with each other [12]. Increasing unemployment and job insecurity are the major stressors to individuals' work and family lives [29]. Too many work hours or inflexibility in work hours are major problem for families, leaving insufficient time and energy for family life [29]. Due to the economic recession, both the parents have to work and parental feelings of not spending enough time with children are widespread [30]. Juggling responsibilities for work, housework, and child-care can become strenuous resulting in workfamily conflict [30]. Employers should have the awareness about the drawbacks of work overload. Because studies have shown that those people who work long hours mostly show their dissatisfaction towards their job. Heavy work to do in limited amount of time makes it difficult for people to handle them and leads to anxiety and frustration.

This study had several potential limitations. Since this was a cross-sectional study so temporality could not be established. Secondly, the sample was obtained from the urban areas; so future studies are warranted on this issue to compare the differences in lives of people living in urban or rural areas. Thirdly, information on some variables such as physical health, psychological health was based on patients' self-report and we could not verify the validity of the information. Furthermore, this research was conducted in one of the cities of Pakistan, so extrapolation of the study results to other populations should be done with caution. 
Conclusion and Recommendations:

In today's world the society seems to be speeding up and becoming less empathic and increasingly stressful. The chronic exposure to stress can have delirious effects on the physical and mental health of the population. Therefore, it is important for patients to take extra measures to keep them healthy to be fit for survival in this fast moving world.

This study found that family life is affected due to less time. This can be managed through family vacations. Studies reveal that that recreation and leisure activities can have positive effects on family cohesion and can assist in reducing stress and increase family bonding, togetherness and harmony which can reverse the effects of psychological issues [30,31].

This study also revealed that fast pace life can have devastating effects on mental health of the people. Studies have proven that prayers and involvement in religious activities have been found to be beneficial in keeping positivity in life [32].

\section{Acknowledgements:}

We are grateful to the management and staff of the study hospitals (Civil Hospital and Aga Khan University Hospital Karachi) for their support throughout the data collection phase. We are also thankful to all the study participants for contributing their information for this study.

\section{References:}

1. Metcalfe F. Revisiting the Twentieth Century. Writer's Showcase Press; 2001.

2. Walljasper J, Reader U. The speed trap. UTNE Reader. 1997(80).

3. Finnish KK, Walton D. Field observations to determine the influence of population size, location and individual factors on pedestrian walking speeds. Ergonomics. 2008;51:827-42.

4. Land FJ, Rastegary H, Thayer J, Colvin C. Time urgency: The construct and its measurement. Journal of Applied Psychology. 1991;76:644.

5. Levine RV, Norenzayan A. The pace of life in 31 countries. Journal of cross-cultural psychology. 1999;30:178-205.

6. Conte JM, Land FJ, Mathieu JE. Time urgency: Conceptual and construct development. Journal of Applied Psychology. 1995;80:178.

7. Kiely KM, Butterworth P. Social disadvantage and individual vulnerability: A longitudinal investigation of welfare receipt and mental health in Australia. Aust N Z J Psychiatry 2013.

8. Pitel L, Geckova AM, Kolarcik P, Halama P, Reijneveld SA, van Dijk JP. Gender differences in the relationship between religiosity and healthrelated behaviour among adolescents. Journal of epidemiology and community health. 2012;66:1122-8.

9. Cole SR, Kawachi I, Liu S, Gaziano JM, Manson $\mathrm{JE}$, Buring JE, et al. Time urgency and risk of nonfatal myocardial infarction. International journal of epidemiology. 2001;30:363-9.

10. Menon S, Narayanan L, Spector P. Time urgency and its relation to occupational stressors and health outcomes for health care professionals. Stress and emotion: Anxiety, anger, and curiosity. 1996;16:127-42.

11. Thoits PA. Stress and Health Major Findings and Policy Implications. Journal of Health and Social Behavior. 2010;51(1 suppl):S41-S53.

12. Cappellini B, Parsons E. Sharing the Meal: Food Consumption and Family Identity. Research in Consumer Behavior. 2012;14:109-28.

13. Kirkcaldy B, Furnham A, Levine R. Attitudinal and personality correlates of a nations pace of life. Journal of Managerial Psychology. 2001;16:20-34.

14. Harris ST, Wong D, Musick D. Spirituality and wellbeing among persons with diabetes and other chronic disabling conditions: A comprehensive review. Journal of Complementary and Integrative Medicine. 2010; 7.

15. Misra A, Chowbey P, Makkar BM, Vikram NK, Wasir JS, Chadha D, et al. Consensus statement for diagnosis of obesity, abdominal obesity and the metabolic syndrome for Asian Indians and recommendations for physical activity, medical and surgical management. JAPI. 2009;57:163-70.

16. Ali NS, Khuwaja AK, Nanji K. Retrospective Analysis of Metabolic Syndrome: Prevalence and Distribution in Executive Population in Urban Pakistan. International Journal of family medicine. 2012.

17. Richardson EA, Pearce J, Mitchell R, Kingham S. Role of physical activity in the relationship between urban green space and health. Public Health 2013.

18. Musick M, Worthen M. Religion and physical health among US adults. Religion, families and health. 2010:248-72.

19. Elhai JD, Palmieri PA, Biehn TL, Christopher Frueh B, Magruder KM. Posttraumatic stress disorder's frequency and intensity ratings are associated with factor structure differences in military veterans. Psychological assessment. 2011;22:723.

20. Brown DR, Carney JS, Parrish MS, Klem JL. Assessing Spirituality: The Relationship Between Spirituality and Mental Health. Journal of Spirituality in Mental Health. 2013;15:107-22.

21. Koenig H, King D, Carson VB. Handbook of religion and health. OUP USA; 2012.

22. Menu A. Survey of research literature regarding the benefits of spiritual care in health care. In: Vancouver Island Health Authority. Retrieved from http://www. viha. ca/NR/rdonlyres/2B7CE521D 34A-462F-949A 3EF610DF36DE/0/ RESEARCHLITERATURESPIRITUALCARE2. pdf; 2009

23. Blazer DG. Religion, spirituality, and mental health: what we know and why this is a tough topic to research. Can J Psychiatry. 2009;54:281-2. 
24. Donahue MJ, Benson PL. Religion and the well being of adolescents. Journal of Social Issues. 1995;51:145-60.

25. Koenig HG. Is religion good for your health: The effects of religion on physical and mental health. Routledge; 1997.

26. Levin J. Religion and mental health: Theory and research. International Journal of Applied Psychoanalytic Studies. 2010; 7:102-15.

27. Morton KR, Lee JW, Haviland MG, Fraser GE. Religious Engagement in a Risky Family Model Predicting Health in Older Black and White Seventh-day Adventists. Psycholog Relig Spiritual. 2012; 4:298-311.

28. McEwen BS. Early life influences on lifelong patterns of behavior and health. Mental retardation and developmental disabilities research reviews. 2003;9:149-54.

29. Halpern DF. How time flexible work policies can reduce stress, improve health, and save money. Stress and Health. 2005; 21:157-68.

30. Buswell L, Zabriskie RB, Lundberg N, Hawkins AJ. The relationship between father involvement in family leisure and family functioning: The importance of daily family leisure. Leisure Sciences. 2012; 34:172-90.

31. Hornberger LB, Zabriskie RB, Freeman P. Contributions of family leisure to family functioning among single-parent families. Leisure Sciences 2013;32:143-161

32. Wagner J. Spiritually Integrated Psychotherapy. Understanding and Addressing the Sacred. Journal of Psychology and Christianity 2009;28:373 